STUDI

FRANCESI

\section{Studi Francesi}

Rivista quadrimestrale fondata da Franco Simone

177 (LIX | III) | 2015

Varia

\title{
Aa. Vv., Des «arrests parlans». Les arrêts notables à la Renaissance entre droit et littérature, études réunies et publiées par G. Cazals et S. Geonget
}

\section{Sabine Lardon}

\section{(2) OpenEdition}

Journals

Édition électronique

URL : http://journals.openedition.org/studifrancesi/1291

DOI : 10.4000/studifrancesi.1291

ISSN : 2421-5856

Éditeur

Rosenberg \& Sellier

\section{Édition imprimée}

Date de publication : 1 décembre 2015

Pagination : $576-577$

ISSN : 0039-2944

\section{Référence électronique}

Sabine Lardon, «Aa. Vv., Des «arrests parlans». Les arrêts notables à la Renaissance entre droit et littérature, études réunies et publiées par G. Cazals et S. Geonget », Studi Francesi [En ligne], 177 (LIX I III) | 2015, mis en ligne le 01 décembre 2015, consulté le 13 janvier 2021. URL : http://

journals.openedition.org/studifrancesi/1291; DOI : https://doi.org/10.4000/studifrancesi.1291

Ce document a été généré automatiquement le 13 janvier 2021.

\section{cc) (†) $\odot$}

Studi Francesi è distribuita con Licenza Creative Commons Attribuzione - Non commerciale - Non opere derivate 4.0 Internazionale. 


\title{
Aa. Vv., Des «arrests parlans». Les arrêts notables à la Renaissance entre droit et littérature, études réunies et publiées par G. Cazals et S. Geonget
}

\author{
Sabine Lardon
}

\section{RÉFÉRENCE}

AA. VV., Des «arrests parlans». Les arrêts notables à la Renaissance entre droit et littérature, études réunies et publiées par G. CAZALS et S. GEONGET, Genève, Droz, 2014, pp. 268.

1 Cet ouvrage réunit les actes du colloque qui s'est tenu les 2 et 3 juin 2011 au CESR de Tours dans le but d'étudier, selon une approche pluridisciplinaire, le rôle des grands arrêts (c'est-à-dire des arrêts de justice ayant fait jurisprudence sur un point notable) à la fin du moyen âge et aux débuts des temps modernes, au temps de la genèse de l'arrestographie.

2 Après l'introduction de Géraldine CAZALS et Stephan GEONGET (pp.7-16), le volume s'articule en trois chapitres. Chapitre 1: «De la pratique à l'arrêt notable».

3 Patrick ARABEYRE (L'ombre portée du parlement de Paris sur le premier recueil d'arrêts toulousain (début du XVI siècle), pp. 19-42) poursuit l'étude, déjà entamée par ailleurs, d'un recueil d'arrêts du parlement de Toulouse. La comparaison méthodique de ses différentes éditions (de l'édition lyonnaise de 1513-1514 à la quatrième édition, à Paris en 1551, en passant par les rééditions lyonnaises de 1513 et 1516) permet de montrer comment le projet initial d'Étienne Aufréri d'élever un monument à la mémoire du parlement de Toulouse se voit progressivement infléchi par la part grandissant d'arrêts du parlement de Paris (pour aboutir à une proportion de 97 arrêts toulousains contre 314 arrêts parisiens dans l'édition parisienne établie par Charles Du Moulin en 1551). Marie houllemare (De la collecte aux collections d'arrêts du parlement de Paris au XVI siècle, 
pp. 43-57) interroge la pratique des collecteurs d'arrêts, qui assistent aux audiences et consignent les arrêts dans des recueils manuscrits à usage personnel, afin de dégager leurs motivations selon le moment de leur carrière juridique, du jeune avocat en formation qui cherche ainsi à compléter, par la pratique, une formation essentiellement théorique, à l'avocat en exercice, qui se montre plus sensible dans sa collecte à l'art oratoire de ses confrères ou au magistrat qui ne retient que la décision de justice. Xavier GoDIN (Prolégomènes aux premiers recueils d'arrêts notables du parlement de Bretagne, pp.59-83) s'intéresse aux arrêts notables à travers les recueils de deux arrêtistes bretons, Noël Du Fail et Guillaume de Lesrat, afin de dégager l'intérêt de ces recueils souvent controversés, mais qui permettent d'instruire les praticiens et nous font mesurer aujourd'hui l'importance de la jurisprudence. Sonia VERNHEZ RAPPAZ (Avis de droit ou arrêts «notables», la jurisprudence à Genève au XVI siècle, pp. 85-99) rappelle également cette valeur des recueils d'arrêts notables qui, dès le XIII ${ }^{\mathrm{e}}$ siècle concourent à consolider les institutions juridiques et à éclairer les praticiens. Elle montre comment l'essor, au $\mathrm{XVI}^{\mathrm{e}}$ siècle, des recueils imprimés relève d'une volonté de promouvoir la jurisprudence locale dans un contexte de multiplication des parlements de province, en contribuant à dégager une interprétation commune de sources multiples (droit romain, droit coutumier, ordonnances). La comparaison entre les avis de droit genevois et la pratique des arrêts en France permet de dégager les différences entre les deux systèmes juridiques.

Chapitre 2: «L'écriture des arrêts notables». Valérie HAYAERT ("Serio ludere» et humanisme juridique: les Gloses de Benoit Le Court aux "Arrêts d'Amour" de Martial d'Auvergne, pp.103-126) se penche sur le commentaire de Benoit Le Court aux Arresta Amorum de Martial d'Auvergne, mélange d'érudition humaniste et de posture philosophique ironique et plaisante, appliquant au commentaire juridique le principe horacien: vertere serio ludi (AP, 226). Olivier DESCAMPS (Quelques remarques sur certains aspects de la responsabilité dans les arrêts notables de Jean Papon, pp. 127-141) montre comment le genre de l'arrêt notable s'inscrit à la croisée de la littérature et du droit, à travers l'étude d'un recueil de Jean Papon (1556) qui se signale par l'emploi du français et la collecte d'arrêts de plusieurs parlements de France, les références fréquentes à la législation royale et une sélection subjective, en particulier attentive à ce qu'on appelle de nos jours la notion de «responsabilité». Bruno MÉNIEL (Les "Plus notables et solennels arrests du Parlement de Bretagne" de Noël du Fail, pp.143-157) se consacre pour sa part aux arrêts bretons recueillis par Noël Du Fail afin de montrer comment ce dernier assume une véritable posture d'auteur, soucieux de faire œuvre utile après avoir été écarté de ses fonctions de conseiller au parlement de Bretagne en raison de ses confessions religieuses, dénonçant les tares de la justice (comme la démultiplication des procès) et élaborant un recueil varié (par la diversité des cas traités et des milieux sociaux retenus). Stephan GEONGET (Louis le Caron, l'écriture de l'arrêt notable entre droit et littérature, pp. 159-178) s'inscrit également à la croisée de la littérature et du droit en montrant comment Louis Le Caron témoigne d'une double volonté de fonder d'une part un droit français clair, émancipé de la tradition italienne et romaine et d'illustrer d'autre part la langue française en faisant de la littérature un auxiliaire de l'écriture juridique. Chapitre 3: «Ambitions et autorité des arrêts».

6 Jean-Louis tHIREAU (Les flottements de l'arrestographie au XVI siècle: les "Décisions notables" de Gilles Le Maistre, pp.181-202) rappelle l'importance controversée des recueils 
d'arrêts: si chaque cour possède ses recueils, ceux-ci ont leurs partisans, mais aussi leurs détracteurs, qui dénoncent le caractère subjectif et incertain de la transcription, de la sélection et de l'interprétation des arrêts. Ceux-ci ne ressortissent pas de fait à une pratique réglée. Manuscrits ou imprimés, ils peuvent être d'un usage privé ou public, hésiter entre le recueil construit ou la simple compilation. L'étude du recueil de Gilles Le Maistre, publié sous un format insolite (in-12) et ordonné en plusieurs traités distincts, permet de montrer comment l'auteur se pose «en architecte et non en simple maçon» (p. 190), afin de produire un recueil encore imparfait certes, mais déjà construit. Géraldine CAZALS (Les arrêts notables et la pensée juridique de la Renaissance, pp. 203-224) rappelle également la méfiance suscitée par ces recueils dont le recensement reste à faire, tant au niveau des cours locales qu'à l'échelle nationale. L'étude diachronique montre comment le recueil d'arrêts se développe depuis la fin du moyen âge en s'émancipant de manière progressive des genres juridiques médiévaux (recueil de notables et questiones), avec lesquels ils peuvent encore présenter des points de contact. De composition et de qualité littéraire variées, le recueil d'arrêt naît de l'évolution des procédures judiciaires et reflète les enjeux juridiques d'une époque soucieuse de codifier et de rationaliser le droit. Nicolas WAREMBOURG ( Non exemplis sed legibus». L'autorité des arrêts à la lumière des droits savants, pp. 225-240) interroge la valeur juridique même de l'arrêt en se demandant si les précédents peuvent constituer une base légale suffisante pour motiver une décision judiciaire. Anne ROUSSELET-PIMONT (Valeur et typologie des arrêts d'après les arrêtistes, pp. 241-258) montre que la jurisprudence peut être une source du droit à l'époque, lorsque la décision émane d'une juridiction respectée. Toutes les décisions des cours n'ayant pas la même valeur, il y a donc une typologie des arrêts et seuls certains types pourront prétendre à un caractère normatif, étudié à travers deux recueils, respectivement de Louis Le Caron et Bernard de La Roche-Flavin.

7 En réunissant les contributions d'historiens du droit et des lettres, ce volume (complété par un index des noms d'auteurs) constitue une étude très riche de la pratique des recueils d'arrêts dont elle permet d'envisager à la fois l'ambiguïté (recueils à la fois controversés et utiles - aussi bien pour les juristes de l'époque que pour les chercheurs d'aujourd'hui), l'hétérogénéité (usage individuel ou public, diffusion manuscrite ou imprimée, variété typologique, construction variée...) et la valeur à la fois juridique et littéraire (dans le cas d'ouvrages imprimés), à travers la présentation de certains recueils saillants. Témoins des enjeux juridiques d'une époque (développement des parlements de province, multiplication des procès, volonté d'uniformisation de sources plurielles), mais aussi d'un essor de la langue française, ces recueils présentent un intérêt indéniable que le présent volume parvient pleinement à démontrer. 